\title{
Incidence and maternal outcome of twin pregnancy
}

\author{
Bharti Sahu, Pooja Jain*
}

Department of Obstetrics and Gynecology, N. S. C. B. Medical College and Hospital, Jabalpur, Madhya Pradesh, India

Received: 09 June 2018

Accepted: 08 September 2018

\section{*Correspondence:}

Dr. Pooja Jain,

E-mail: jpooja11@gmail.com

Copyright: () the author(s), publisher and licensee Medip Academy. This is an open-access article distributed under the terms of the Creative Commons Attribution Non-Commercial License, which permits unrestricted non-commercial use, distribution, and reproduction in any medium, provided the original work is properly cited.

\begin{abstract}
Background: Twin pregnancy is a high-risk pregnancy with different prevalences in different regions of world which is on the rise due to growing use of assisted reproductive technology. The objective of this study is to determine the incidence and maternal complication and outcome of twin pregnancies.

Methods: This is a prospective observational study conducted in 2016-2017 in NSCB medical college and hospital, Jabalpur on 67 twin deliveries. Final outcome was given in terms of percentage and ratio.

Results: After assessment of 5995 deliveries during the period 2016-2017 the incidence of twin pregnancy was 1.12 percent. In present study $83.6 \%$ of patients were in the age group of 21-30 years. Majority $56.7 \%$ were unbooked. $50.7 \%$ were primipara. Family history of twin pregnancy was found in $31.3 \%$ cases and $17.9 \%$ cases have history of ovulation inducing agent. Maximum 65.7\% delivered between the gestational age 29-37weeks. Mostly 59.7\% were dichorionic-diamniotic twins. Preterm delivery occurred $72.5 \%$ in Diamniotic Dichorionic and $85.7 \%$ in Monoamniotic Monochorionic. 49.3\% cases were having both babies with cephalic presentation. 29.9\% twins delivered by cesarean section. most common indication for LSCS in twin pregnancy was malpresentation. Most common complication was preterm labour $(52.2 \%)$ followed by anaemia and preeclampsia.

Conclusions: Twin pregnancy had higher likelihood of maternal adverse effect. The higher morbidity and mortality is due to high percentage of patient being unbooked and majority receive no therapeutic intervention until admission. So all efforts should directed towards better quality antenatal care of twin carrying mother.
\end{abstract}

Keywords: Anaemia, Maternal complication, Maternal outcome, Twin pregnancy

\section{INTRODUCTION}

Development of two foetuses simultaneously in the uterus is termed as twin pregnancy. ${ }^{1}$ Such pregnancies are associated with increased risk for both mother and child, and this risk increases with the number of offsprings.

Twinning is a result of fertilisation of two separate ova (dizygotic) and about one third of cases arise from division of a single ovum into two separate embryo (monozygosity). ${ }^{2}$ Multiple gestations are becoming a problem of increasing dimensions with the dramatic increase in numbers due to a trend towards late childbearing and the widespread use of assisted reproduction. The Worldwide incidence of multiple pregnancies varies considerably, it is around 2 -20 per 1000 births $^{3}$.

Highest burden of multiple pregnancies has been found in Sub-Saharan Africa, with an average twinning rate of 20 per 1,000 deliveries compared to 10 per 1,000 deliveries in Europe and around 5-6 per 1,000 deliveries in Asia. ${ }^{4}$

The incidence of monozygotic twins is uniform throughout the world, 3.5 per 1000 live births. In contrast the incidence of dizygotic twins is affected by multiple 
factors and varies between 4 to50 per 1000 livebirths. This wide variation in the incidence of dizygotic twins is due to multiple variables such as the use of artificial reproductive technology, ethnic differences, and maternal age. ${ }^{5}$ The aims and objectives of this study are to study the incidence of twin pregnancies and to evaluate the maternal complications and outcome in twin pregnancy.

\section{METHODS}

Study design: Prospective observational study. Study period: $1^{\text {st }}$ March 2016 to $31^{\text {st }}$ March 2017. Study area: Department of Obstetrics and Gynaecology NSCB Medical College and Hospital, Jabalpur, Madhya Pradesh. Sample size: 67 twin deliveries were observed. Fisher's exact test and chi square test were applied. Final outcome of maternal and perinatal complications was given in terms of percentage and ratio.

\section{Inclusion criteria}

- All women in reproductive age group i.e. 15-45 years.

- Twin gestation with 20 completed weeks.

- All women booked or unbooked delivered in our hospital.

\section{Exclusion criteria}

- Women with gestational age less than 20 weeks.

- Women with more than 2 fetuses (triplets, quadruplets).

\section{Procedure planned}

This study included subjects, fulfilling inclusion criteria, admitted and delivered inGLR, Department of Obstetrics and Gynaecology, NSCB Medical College and Hospital, Jabalpur, Madhya Pradesh.

- Informed consent was taken from the subjects to be included in study.

- History of spontaneous conception, intake of ovulation inducing agent and previous medical diseases were taken.

- Detailed Obstetrics history was recorded.

- General physical examination, per abdominal examination, pelvic examination was done.

- Required investigations were done.

- Socio-demographic data collected.

- Placenta examined to confirm the chorionicity.

- Study was conducted during antenatal, labour and post-natal period till the patient discharged.

- Appropriate statistical methods were applied.

Continuous maternal and fetal monitoring was implemented throughout labor. Mode of delivery was planned with the decision based on fetal conditions, presentation and other obstetrical indication. Help from other faculties as competent pediatrician and anesthetist were called for in anticipation of any fetal and maternal complications respectively. Careful watch was kept over mother and babies.

\section{RESULTS}

During one-year study period 67 patients presented with twin pregnancy out of 5995 deliveries. This yielded an incidence of $1.12 \%$. Majority $(56.7 \%)$ of the patient had not received quality antenatal care, they were unbooked. Maximum twin pregnancy mothers were in age group of $21-30 y e a r s(83.6 \%)$. The next larger group is more than 30 years age (Table 1$)$.

Table 1: Demography and obstetrics characteristics of the study $(n=67)$.

\begin{tabular}{|lll|}
\hline $\begin{array}{l}\text { Demography and } \\
\text { obstetrics characteristics }\end{array}$ & Frequency & Percentage \\
\hline \begin{tabular}{l} 
Age (year) \\
\hline$<21$ years
\end{tabular} & 5 & 7.5 \\
\hline 21-30 years & 56 & 83.6 \\
\hline$>30$ years & 6 & 9.1 \\
\hline Total & 67 & 100 \\
\hline Gestational Age & & \\
\hline$\leq 28$ weeks & 6 & 9 \\
\hline 29-36 weeks & 44 & 65.7 \\
\hline$\geq 37$ weeks & 17 & 25.4 \\
\hline Total & 67 & 100 \\
\hline Parity & & \\
\hline Primi & 34 & 50.7 \\
\hline $2-3$ & 23 & 34.3 \\
\hline$>3$ & 10 & 14.9 \\
\hline Total & 67 & 100 \\
\hline
\end{tabular}

Majority cases were from rural area $(67.2 \%)$ and $32.8 \%$ from urban area. In our study $38.8 \%$ cases are educated up to middle class, $26.9 \%$ cases educated up to primary level and 6\% cases were illiterate. $70 \%$ cases belonged to lower Socio-economic status. Family history of twin pregnancy was present in $31.3 \%$ cases. In the present study conception occurred spontaneously in $82.1 \%$ cases, while in $17.9 \%$ cases conception occurred after the use of ovulation inducing agent (Table 2).

Table 2: Distribution of cases according to probable etiological factors.

\begin{tabular}{|lcc|}
\hline Parameters & \multicolumn{1}{|c|}{ Frequency } & Percentage \\
\hline Family history of twin pregnancy & \\
\hline Present & 21 & 31.3 \\
\hline Absent & 46 & 68.7 \\
\hline Total & 67 & 100 \\
\hline History of taking & ovulation inducing agent \\
\hline Present & 12 & 17.9 \\
\hline Absent & 55 & 82.1 \\
\hline Total & 67 & 100 \\
\hline
\end{tabular}


In present study $74.6 \%(65.7 \%+9 \%)$ twin pregnancy cases delivered preterm (before 37 weeks gestation) and $25.4 \%$ cases delivered after term gestation. Majority $50.7 \%$ twin pregnancy cases were primipara (Table 3 ).

Table 3: Distribution of cases according to maternal complication.

\begin{tabular}{|lll|}
\hline $\begin{array}{l}\text { Complication } \\
\text { Anaemia (moderate and } \\
\text { severe) }\end{array}$ & 20 & 29.9 \\
\hline Preeclampsia & 20 & 29.9 \\
\hline Abruptio placenta & 3 & 4.5 \\
\hline Preterm (<34 weeks) & 35 & 52.2 \\
\hline Hyperemesis gravidarum & 1 & 1.5 \\
\hline Eclampsia & 10 & 14.9 \\
\hline PROM & 16 & 23.9 \\
\hline PPH & 3 & 4.5 \\
\hline Total & 108 & $>100$ \\
\hline
\end{tabular}

In this study $49.3 \%$ cases were having both babies with cephalic presentation and this was the commonest of all combination of presentation. Second most common presentation was vertex-breech $(19.4 \%)$ and third common presentation was breech-breech (14.9\%) (Figure $1)$.

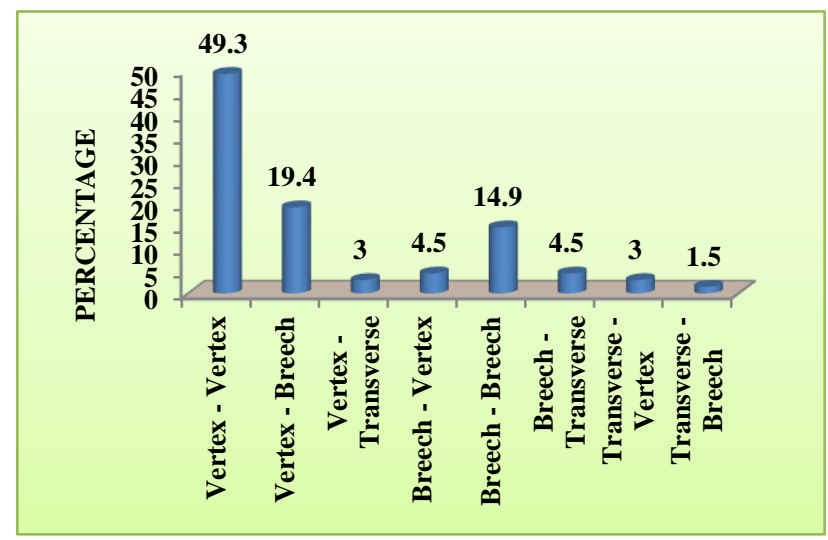

Figure 1: Distribution of cases according to presentation at the time of birth.

In present study mostly $59.7 \%$ were dichorionicdiamniotic twins, $29.9 \%$ monochorionic-diamniotic twins, and $8.9 \%$ were monochorionic-monoamniotic twins. According to mode of delivery most of $68.7 \%$ cases of twin pregnancy delivered vaginally, cesarean section was done in $20 \%$ cases. Only one case $1^{\text {st }}$ baby delivered vaginally and $2^{\text {nd }}$ baby delivered by cesarean section (Figure 2).

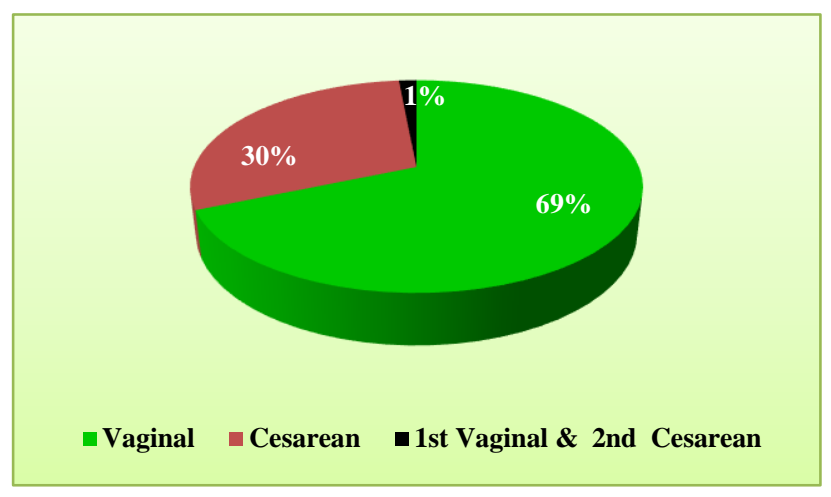

Figure 2: Distribution of cases according to mode of delivery.

Most common indication for caesarean section in twin pregnancy was $1^{\text {st }}$ baby other than cephalic presentation which was $57.1 \%$, $2^{\text {nd }}$ most common $23.8 \%$ was antepartum eclampsia. In only one case reason was $1^{\text {st }}$ cephalic and $2^{\text {nd }}$ baby transverse lie (Figure 3 ).

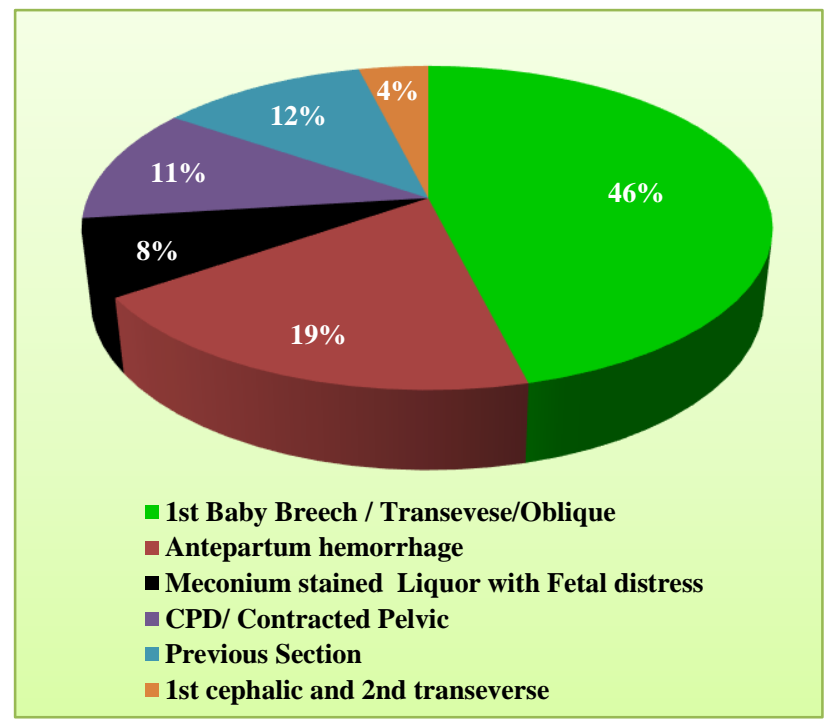

Figure 3: Distribution of cases according to indication of LSCS.

Table 4: Association between onset of labor and placenta chorionicity.

\begin{tabular}{|llll|}
\hline Onset of labor & Diamniotic-dichorionic & Diamniotic-monochorionic & Monoamniotic-monochorionic \\
\hline Preterm labor $(<37$ weeks $)$ & $31(72.1 \%)$ & $14(77.8 \%)$ & $5(83.3 \%)$ \\
\hline Term labor & $12(27.9 \%)$ & $4(22.8 \%)$ & $1(16.7 \%)$ \\
\hline Total & $43(100 \%)$ & $18(100 \%)$ & $6(100 \%)$ \\
\hline
\end{tabular}


In present study, interval between the delivery of two fetuses was not more than 20 minutes, except only in one case where caesarean section was performed for delivery of second twin. Preterm deliveries more in monoamniotic-monochorionic twins (83.3\%) as compared to diamniotic-monochorionic twins $(77.8 \%)$ and diamniotic-dichorionic twins (72.1\%) (Table 4).

\section{Maternal outcome}

In this one-year study, out of 67 cases 2 cases died due to antepartum eclampsia and severe anaemia. Both cases were unbooked. Most common maternal complication was preterm labor occurring in $52.2 \%$ cases, followed by anaemia in $29.9 \%$ cases, preeclampsia in $29.9 \%$ cases, premature rupture of membrane occurred in $23.9 \%$ cases followed by eclampsia in $14.9 \%$ cases. Other complications were abruptioplacantae, postpartum haemorrhage and hyperemesis gravidarum. Maternal complications mostly occurred in unbooked cases (Table 2).

\section{DISCUSSION}

Twin pregnancy is a high-risk pregnancy with unique complications which have important implications on the maternal outcome, compared to singleton pregnancy. It is also a high-risk delivery especially so for the second twin. The present study was carried out in 67 cases of twin pregnancy admitted and delivered in Department of Obstetrics and Gynaecology, N.S.C.B Medical College, Jabalpur, Madhya Pradesh, India from $1^{\text {st }}$ March 2016 to $1^{\text {st }}$ March 2017.

\section{Incidence}

Incidence of twin pregnancy varies from country to country. Highest rate is seen in African American women and lower in white women, Hispanic, Asian and Native American women comparatively. In this study, the Incidence of twin deliveries during the period 2016-17 observed was 1.12 percent. Sanjay P et al, 2016 reported incidence was $1.7 \%{ }^{1}$ Latasingh et al, 2017 showed incidence was $1.85 \% .^{3}$ Pandey MR et al,2015 showed incidence of twin pregnancy is $1.9 / 1000$ live births. ${ }^{5}$ Assucao RA et al, 2010 reported the incidence of twin pregnancy $3.4 \%{ }^{6}$

\section{Maternal age}

In this study, it was found that $83.6 \%$ of patients were in the age group of 2130 years. $7.5 \%$ were $<21$ year and $9 \%$ were >30years old. Mean age is higher in twin pregnancy. Sanjay P et al, 2016 reported $89 \%$ of the mothers were in age group of 21-30 years. ${ }^{1}$ Pandey MR et al, 2015 showed mean maternal age was $20-25$ year in $37.4 \%$ cases. $^{5}$ Bhavanas et al, 2014 reported, $73.3 \%$ cases were in mean age group of 20-25 years. ${ }^{7}$ In all study higher incidence of twinning was in age group of 21-30 years.

\section{History of twin pregnancy in family}

In this study, family history of twinning was found in $31.3 \%$ of cases, which is similar to the study conducted by Pandey MR et al, 2015 reported family history of twin pregnancy in $4.3 \%$ cases..$^{5}$ Sultana et al, 2011 reported that $36 \%$ of mothers showed family history of twin pregnancy. ${ }^{8}$

\section{History of ovulation inducing agent}

In this study $17.9 \%$ cases have history of ovulation inducing agent for conception. Sanjay P et al, 2016 reported that $34 \%$ of the twins occurred after the use of ovulation inducing agent. ${ }^{1}$ Pandey MR et al, 2015 showed $2.2 \%$ of twin occurred after use of ovulation inducing agent. ${ }^{5}$

\section{Quality care (booked/ unbooked)}

In this study $56.7 \%$ cases were unbooked. This shows lack of accessibility to antenatal services by majority of women. Sanjay P et al, 2016 showed $41 \%$ cases were unbooked. ${ }^{1}$ Pandey MR et al, 2015 showed $95.7 \%$ cases were unbooked. ${ }^{5}$

\section{Parity of mother}

In this study, $50.7 \%$ females were primipara and $14.9 \%$ were multipara. Sanjay P et al, 2016 showed mostly cases were primigravida $(70 \%) .{ }^{1}$ In veronica et al most cases were primigravida $(48 \%){ }^{9}$ This may be attributed to the increasing number of patients with infertility, treated with ovulation induction.

\section{Gestational age}

In this study maximum $(65.7 \%)$ delivered between the gestational age 29-37 weeks. Pandey MR et al, 2015 showed mean gestational age was 34.6 week and mostly delivered between33-36week of gestation. ${ }^{5}$ Rizwana et al (2010) most of the women presented with preterm labour at before 36 weeks $(84 \%){ }^{10}$ The duration of gestational age is shorter in multiple pregnancy due to undue stretching of uterus and excessive enlargement of uterus leading to early ripening of cervix and loss of polarity of uterus.

\section{Presentation of twins}

In this study $49.3 \%$ cases were having both babies with cephalic presentation and this was the commonest of all combination of presentation. Second most common presentation was vertex-breech (19.4\%) and third common presentation was breech-breech (14.9\%). In Sultana et al (2011) showed 98\% vertex- vertex, $16 \%$ vertex-nonvertex and $36 \%$ nonvertex (first twins). ${ }^{8}$ Thus there is high incidence of malpresentation at the time of delivery in twin gestation. 


\section{Chorionicity of placenta}

In our study mostly $59.7 \%$ were dichorionic-diamniotic twins, 29.9\% were monochorionic-diamniotic twins, and $8.9 \%$ were monochorionic-monoamniotic twins. Preterm delivery occurred $72.5 \%$ in diamniotic-dichorionic and $85.7 \%$ in monoamniotic-monochorionic. Katarzyna Kosinska Kaczunska et al (2016) this study shows dichorionic twins $(76.6 \%)$ and monochorionic twins were $23.4 \%$, including $1.7 \%$ monochrionic-monoamniotic twins. ${ }^{11}$ In this study $66.5 \%$ of the women delivered before 37 weeks of gestation, significantly more women in the monochorionic than the dichorionic group.

\section{Mode of delivery}

In this study most common mode of delivery in twin pregnancies are vaginal (68.7\%). Pandey MR et al, 2015 showed mostly $54 \%$ of cases delivered vaginally. ${ }^{5}$

\section{Indication for cesarean section}

In present study the most common indication for LSCS in twin pregnancy was $1^{\text {st }}$ baby other than cephalic presentation which was $57.1 \%$, 2nd most common $23.8 \%$ was APE. CPD and previous section present in $14.3 \%$ and $14.3 \%$ cases respectively. Sanjay P et al 2016, reported most common indication for caesarean section was malpresentation in $50 \%$ cases. $^{1}$

\section{Maternal outcome}

In this study out of 67,2 cases died due to maternal complication APE and severe anaemia. Most common complication was preterm labour $(52.2 \%)$ followed by anaemia in $29.9 \%$ cases, preeclampsia in $29.9 \%$ cases, PROM occurred in $23.9 \%$ cases followed by eclampsia in $14.9 \%$ cases. Other complications were abruptio placentae, PPH and hyperemesis gravidarum. Maternal complication occurred more in unbooked cases.

Sanjay $\mathrm{P}$ et al, 2016 most common complication was preterm labor (70\% cases). ${ }^{1}$ Singh L et al, 2017 showed preterm labor in $74.7 \%$ cases, anaemia in $44 \%$ cases, PIH in $32 \%$ cases and PPH in $13.33 \%$ cases. ${ }^{3}$ Pandey MR et al, 2015 showed four leading maternal complications were preterm $62.58 \%$ cases, anaemia $8.6 \%$ cases, PIH in $5 \%$ cases and APH in $2.2 \%$ cases. $^{5}$ Saravanan $\mathrm{S}$ et al, 2017 showed maternal complications was PROM in $13.3 \%$ cases, $\mathrm{PPH}$ in $6.7 \%$ cases, PIH in $20 \%$ cases and anaemia in $33.3 \%$ cases. $^{12}$ Thus the most common complication was preterm labor. Anaemia is found to be more frequent in twin pregnancy because, iron demand is increased due to increase in red call mass and the additional iron requirement of two fetuses.

\section{CONCLUSION}

Twin pregnancy had higher likelihood of maternal and fetal adverse outcome. Multiple pregnancies were more frequently associated with complication like pregnancy induced hypertension, anaemia, malpresentation, preterm labor and postpartum hemorrhage. The incidence of low birthweight babies was quite high in twin pregnancy. The higher morbidity and mortality is due to high percentage of patient being unbooked and majority receive no therapeutic intervention until admission. In conclusion the basic mantra to prevent the maternal morbidity and mortality:

- Better quality antenatal care of twin carrying mother with frequent antenatal visits, awareness and educating them regarding antenatal care and taking extra precautions for better outcome.

- By prevention and early detection of complication like anaemia, preeclampsia, survival rate of women and babies can be improved to a great extent in developing countries.

- Early referral of twin pregnant mother to an Institution with proper ultrasound facilities and neonatal intensive care unit.

- Counselling and close monitoring of women using ovulation inducing therapies. We can also reduce the frequency of twins pregnancy in first place, includes limiting the number of embryos transferred in IVF.

- There is a need for quality obstetric care health services to get a better fruitful outcome.

- To combat this health problem, drastic changes are needed which requires active participation of community, government and nongovernment organization doctors and nurses every pregnancy should be culminate in: healthy mother and healthy baby.

Funding: No funding sources Conflict of interest: None declared

Ethical approval: Not required

\section{REFERENCES}

1. Nimbalkar PS, Bava A, Nandanwar Y. Study of maternal and foetal outcome in multifetal pregnancy. Int J Reprod Contracept Obstet Gynecol. 2016;5(10):3478-81.

2. Rezavand N, Veisi F, Malek-Khosravi S, Zangeneh M, Kohzadi M. Assessment of Frequency of Twin Pregnancy and Neonatal Outcome in Deliveries of Mo'tazedi Hospital, Kermanshah in 2004-2007. J Obstet Gynecol India. 2014;64(1):19-22.

3. Singh L, Trivedi K. Study of maternal and fetal outcome in twin pregnancy. Int J Reprod Contracept Obstet Gynecol. 2017;6(6):2272-8.

4. Qazi G. Obstetric and perinatal outcome of multiple pregnancy. J Coll Physicians Surg Pak. 2011;21(3):142-5.

5. Pandey MR, Kshetri BJ, Dhakal D. Maternal and perinatal outcome in multifetal pregnancy: a study at a teaching hospital. Am J Public Health Res. 2015;3(5A):135-8. 
6. Assunção RA, Liao AW, Brizot MD, Krebs VL, Zugaib M. Perinatal outcome of twin pregnancies delivered in a teaching hospital. J Brazilian Med Assoc. 2010;56(4):447-51.

7. Bhavana S, Shivanna S, Gopal N. A study on fetomaternal outcome in twin gestation in a tertiary rural health centre. IJARMS. 2004;1(1):15-7.

8. Sultana M, Khatun S, Saha AK, Akhter P, Shah AB. Maternal and perinatal outcome of twin pregnancy in a tertiary hospital. Ibrahim Cardiac Med J. 2011;1(2):35-9.

9. Irene YV, Vaneet K. An analytical study of pregnancy outcome in multifetal gestation. J Obstet Gynecol India. 2007;57(6):509-12.

10. Rizwan N, Abbasi RM, Mughal R. Maternal morbidity and perinatal outcome with twin pregnancy. J Ayub Med Coll Abbottabad. 2010;22(2):105-7.

11. Kosińska-Kaczyńska K, Szymusik I, Bomba-Opoń D, Olejek A, Sławska H, Zimmer M, et al. Perinatal outcome according to chorionicity in twins-a Polish multicenter study. Polish Gynecol. 2016;87(5):384-9.

12. Saravanan S, Loganathan M. Perinatal outcome of multiple pregnancy. Int J Reprod Contracept Obstet Gynecol. 2017;6(6):2226-30.

Cite this article as: Sahu B, Jain P. Incidence and maternal outcome of twin pregnancy. Int J Reprod Contracept Obstet Gynecol 2018;7:4506-11. 